\title{
MARKOV MODEL TABANLI ÇİFT ENSTRUMANLI MÜZİK BESTELEME
}

\author{
Muratcan KILIÇ, H. İrem TÜRKMEN*
}

Ylldız Teknik Üniversitesi, Elektrik-Elektronik Fakültesi, Bilgisayar Mühendisliği Bölümü, İstanbul, Türkiye

Anahtar Kelimeler
Markov Model,
Otomatik Müzik Besteleme,
Cift Enstruman.

\section{Öz}

Müzik, tarih boyunca insan eliyle üretilen tonlar dizilimi olarak gerçeklenmiştir. Son altmış yılda müziğin otomatik olarak bilgisayarlar yardımıyla bestelenmesi ile ilgili çalışmalar yapılmaktadır. Bu çalışmada, müziğin otomatik olarak üretilmesinde Markov süreci yaklaşımının kullanıldığı özgün bir müzik besteleme sistemi, EMERSON, sunulmuştur. EMERSON'ın insan yapımı müziklerin performansına ne kadar yaklaşabileceğinin tahlili yapılmıştır. Bunun için önerilen sistemde literatürdeki diğer çalışmalardan farklı olarak iki enstrümanlı parçalar üretilmiştir. Birinci enstrümanın eğitiminde bir insan yapımı beste, ikinci enstrümanın eğitiminde birinci enstrümanın müzik sekansı kullanılmıştır. Üretilen müziklerin performansı anket yoluyla ölçülmüştür. Anketin Turing testi kısmında \%43.32 oranında başarı oranı, beğeni testinde ise 10 üzerinden ortalama 5.62 puan elde edilmiștir.

\section{COMPOSITION OF MUSIC WITH DUAL INSTRUMENTS BASED ON MARKOV MODEL}

\section{Keywords Markov Model, Automated Music Composition, Dual Instruments.}

\begin{abstract}
Music has been implemented as a human-made sequence of tones throughout the history. In the last sixty years, there are ongoing studies about automated composition of music by computers. In this study, we propose a novel system, referred to as EMERSON, which exploits Markov process in order to perform automated composition of music. It has been analyzed that whether automatic composed music is approximated or not to the performance of the human-made music. For this purpose, differently from the works in technical literature, twoinstrument pieces are generated by the proposed study. First instrument sequence is trained by using human-made composition while sequence of second instrument is trained by using the produced sequence of the first instrument. Performance evaluation of generated music is performed by surveying. In the Turing test part of survey it has been achieved $43.32 \%$ success rate, whereas in liking test a success rate of 5.62 points out of 10 is calculated.
\end{abstract}

Alıntı / Cite

Kılıç, M., Türkmen, H. İ., (2020). Markov Model Tabanlı Çift Enstrumanlı Müzik Besteleme, Mühendislik Bilimleri ve Tasarım Dergisi, 8(4), 1236-1247.

\begin{tabular}{l|l|l}
\hline Yazar Kimliği / Author ID (ORCID Number) & \multicolumn{3}{|l}{ Makale Süreci / Article Process } \\
\hline M. Kılıç, 0000-0003-2172-5716 & Başvuru Tarihi / Submission Date & 28.04 .2019 \\
H. İ. Türkmen, 0000-0002-8690-0725 & Revizyon Tarihi / Revision Date & 30.09 .2020 \\
& Kabul Tarihi / Accepted Date & 21.12 .2020 \\
& Yayım Tarihi / Published Date & 25.12 .2020 \\
\hline
\end{tabular}

\section{Giriş (Introduction)}

Müzik, insanlık tarihinin başından beri uygulanan, sesin estetiği üzerine kurulmuş, sanatın en eski dallarından biridir. Tarih boyunca müzisyenler müziğin nasıl geliştirilebileceği ve otomasyona dayalı matematiksel bir teknikle nasıl işlenebileceği sorusuna odaklanmış, bu amaçla çeşitli altyapılar, prosedürler, algoritmalar ve istatistiksel yöntemler geliştirmişlerdir. Bu konuda ilk olarak, Wolfgang Amadeus Mozart ve Franz Joseph Haydn

\footnotetext{
${ }^{*}$ ilgili yazar / Corresponding author: irem@yildiz.edu.tr, +90-212-383-5763
} 
1793 yılında zar atmaya dayalı, bilinen en eski "otomatik" müziklerden birisini geliștirmiştir(Hedges, 1978). Elektronik bilgisayarların icat edilmesi ve gelişmesiyle birlikte bu çalışmalar hız kazanmış ve daha farklı bir boyut almıştır.

Bu çalıșmada ikinci mertebe Markov süreci kullanılarak bilgisayar tarafından otomatik olarak müzik bestelenmesi sağlanmıștır. Sürecin zaman içinde geliştirilmesi ile müzik besteciliğinde kullanılan sezgisel prosedürlerin ne dereceye kadar matematiksel olarak ifade edilebileceğinin gözlemlenmesi hedeflenmektedir.

Markov tabanlı çift enstrumanlı otomatik müzik besteleme sisteminin çalışma adımları Şekil 1'de gösterilmiştir.

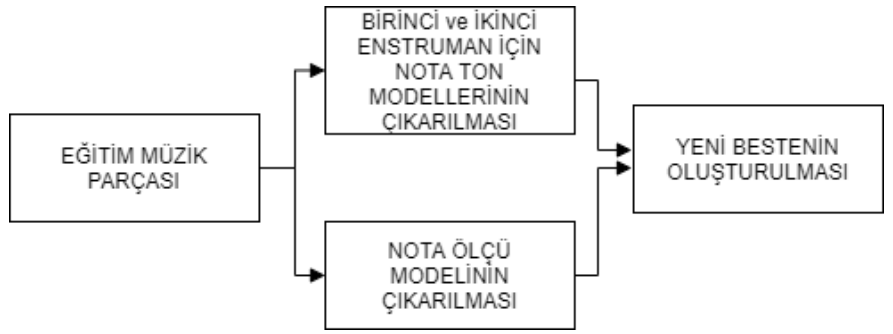

Şekil 1. Sistem Akış Diyagramı (System Flow Diagram)

Önerilen sistemde eğitim için kullanılacak müzik parçasının nota geçiș özellikleri kullanılarak birinci ve ikinci enstruman için Markov nota ton modelleri çıkartılmaktadır. Çalışma çift enstrumanlı müzik bestelemektedir. Bu amaçla, ikinci enstrumanın modeli çıkartılırken birinci enstrumanın modelinden yararlanılmaktadır. Eş zamanlı olarak, eğitim parçasının nota ölçülerinden her iki enstruman için de kullanılacak nota ölçü modeli oluşturulur. Son aşamada elde edilen modeller kullanılarak çift enstrumanlı müzik besteleme işlemi tamamlanır.

Çalıșma, diğer otomatik müzik besteleme algoritmalarından farklı olarak Markov sürecinde ikinci bir enstrümanın dahil olmasıyla kendisini eğitim verisine göre yazmak yerine birinci enstrümanın gidiş şekline göre yazmaktadır. Bunu sağlamak için Markov sürecinin eğitiminde birinci enstrümanın çıkış verisi ikinci enstrümanda tekrar girişte kullanılmaktadır.

$\mathrm{Bu}$ makalede müzik teorisiyle ilgili terimler kullanılmıştır. Çalışmanın daha rahat anlaşılabilmesi adına bu terimlerin kısaca açıklamasına ve oluşturulan müzik parçalarından örneklere Ek Materyal bölümünden ulaşılabilir. İkinci kısımda bu çalışmadan önce yapılmış çalışmalar incelenmiş, yapılmış olan çalışmayı ne derecede etkilediği ve çalışmaya nasıl bir katkısı olduğu belirtilmiştir. Üçüncü kısımda Markov sürecinin çalışmada nasıl kullanıldığı anlatılmış ve algoritma detaylı bir şekilde ele alınmıştır. Dördüncü kısımda Turing testi ve beğeni testi metodları kullanılarak otomatik olarak üretilen müziklerin performansları ölçülmüştür. Son kısımda alınan sonuçlar değerlendirilerek önerilen modelin ileride yapılacak çalışmalara katkısı irdelenmiştir.

\section{Kaynak Araştırması (Literature Survey)}

Bilgisayar tarafından üretildiği bilinen ilk müzik örnekleri; Push Button Bertha(Ames, 1987), ILLIAC Suite ve(Westergaard \& Hiller, 1959) Computer Cantata olmuştur(Lejaren A. Hiller and Robert A. Baker, 1964). Push Button Bertha, Adventure Tomorrow isimli bir programda, 9 Ağustos 1956 tarihinde canlı olarak sunulmuştur(Ariza, 2011).

Yapılan çalışmalarda müzik teorisine bağlı olan birçok parametre uygulamaya geçirilmiştir. Bunlar arasında ölçü çizgisi, zaman işareti, tempo (Roig, 2014\}, oktav, akorlar (Muñoz, 2016; Roig, 2018), sus notası (Colombo, 2016) yer almaktadır. Bu çalışmalarda iki farklı yaklaşım benimsenmiștir (Herremans, 2015): Olasılıksal modeller (Roig, 2014; Van der Merwe, 2011; Toivanen, 2013; Mazurowski, 2012; Salas, 2011; Holtzman, 1981; Tanaka, 2010; Lo \& Lucas, 2006) ve optimizasyona dayalı modeller (Muñoz, 2016; Colombo, 2016; Puente, 2002; Burton, 1999; Hornel, 1998; Chen, 2001). Bunlara ek olarak bu iki yapıyı birlikte kullanan çalışmalar da yayınlanmıştır (Herremans, 2015; Boenn, 2011\}.

Olasılıksal modeller arasında farklı yöntemler kullanılmıştır. Üretici gramerler (Salas, 2011; Holtzman, 1981) doğal dil işleme yaklaşımıyla müzik üretimidir ve müzik notalarının bir alfabe olarak kabul edilip anlamsallık olușturulması yoluyla çalıșmaktadır. Olasılıksal modeller arasında yaygın olarak kullanılan Markov zincirleri (Tanaka, 2010; Lo \& Lucas, 2006) ve N-gram tabanlı sistemler (Roig, 2018) önceki olasılıksal geçişlere göre sonraki olasılıksal geçişlere karar veren modellerdir. 
Optimizasyona dayalı modeller olasılıksal modellere göre daha güncel uygulamalardır ancak daha yüksek hesaplama karmaşıklığı gerektirmektedir. Yaygın olarak kullanılan optimizasyona dayalı modeller arasında rastgele bir başlangıç setinden optimizasyon formülüne bağlı olarak gelişen genetik algoritmalar (Muñoz, 2016; Puente, 2002; Burton, 1999) ve yapay sinir ağları (Colombo, 2016; Hornel, 1998; Chen, 2001; Zha, 2019) dikkat çekmektedir.

Literatürdeki çalışmaların bazıları değerlendirme için insanların görüşüne tabi tutulmuştur. Roig ve ekibinin önerdiği modelin anket çalışması ortalama \%64 başarı elde ederken(Roig, 2018), Van Der Merwe'nin anket çalışması \%38 başarı oranı elde edebilmiştir(Van der Merwe, 2011). Bu testlerde, kişilere kısa müzik kesitleri dinletilmiş ve bu kesitlerin insana mı, yoksa bilgisayara mı ait olabileceği sorulmuştur. Bilgisayara ait bir kesitin insan yapımı sanılması miktarı ile dinletilen müzik miktarı arasındaki oran başarı ölçütü olarak ele alınmıştır.

Bu çalışmada önerilen sistem olasılıksal bir model olan Markov zincirlerini kullanmaktadır. Olasılıksal modellerin implementasyonu, optimizasyona dayalı modellere göre daha az hesaplama karmaşıklığına sahiptir.

Roig ve ekibi (Roig, 2018) homojen olmayan bir Markov modeli uygulamıştır. Bu modelde Markov zincirinin geçiş matrisi iki boyutlu değil, üç boyutludur. Üçüncü boyutta nota vuruşları arasındaki geçişler de incelenmiştir. Papadopoulos'un bir çalışmasında Markov zincirlerinin intihale yol açabileceğine ve bunun nasıl önlenebileceğine dair fikirler yer almaktadır (Papadopoulos, 2014). Markov modeli kullanan Tanaka ve ekibinin çalışmasında (Tanaka, 2010) ritim geçişleri insanlar tarafından önceden tanımlanmış kalıplarla oluşturulmuştur.

Markov zincirlerinin tercih edilmesindeki nedenler arasında Markov zincirlerinin istatistiksel doğasının müziğin yapısına uygunluğu yer almaktadır. Müzik, bilgisayarda her notanın bir durum, ve her nota geçişinin bir durum geçişi olarak kabul edilmesiyle modellenir. Üstelik, hesaplama karmaş̧ıklığının ikinci derece için küçük olması, eğlence sektörüne yönelik mobil uygulamalarda kullanılmasında avantaj sağlamaktadır.

Önerilen çalışmanın otomatik müzik besteleme literatürüne üç temel katkısı bulunmaktadır:

- Birbirinden etkilenen iki enstrümanlı müzik bestelerinin, tek enstrüman veya birbirinden bağımsız enstrümanlar kullanılarak üretilen bestelere göre daha başarılı sonuç verdiği gözlemlenmiștir.

- Eğitim için kullanılacak beste uzunluğunun üretilen bestenin başarısına etkisi ortaya konulmuştur.

- Nota ölçüleri da eğitim sürecinin bir parçası olarak sisteme dahil edilmiştir.

Geliştirilen projede ritim geçişlerinde insanlar tarafından önceden tanımlanmış hazır kalıplar kullanılmamış, nota ölçüleri de Markov süreci eğitimine dahil edilmiștir. Önerilen sistemin Markov zinciri ile müzik üreten diğer çalışmalardan başka bir farkı ise üretilen parçanın iki enstrümanlı olması ve ikinci enstrümanın, birinci enstrümanın nota geçişlerinden çıkarılan modeller kullanılarak üretilmesidir.

\section{Materyal ve Yöntem (Material and Method)}

Markov modeli, bilgisayar bilimlerinde yaygın olarak kullanılan bir stokastik süreçtir. Markov modelinin kapsadığı süreçler rastgele değişen durumların simülasyonunda kullanılmaktadır. Eğer Markov modelindeki durumlar dışarıdan izlenebiliyorsa ve ayrık ise, bu sürece Markov zinciri adı verilir. Markov zincirlerinin çalışma ilkesi önceki durum geçişleri baz alınarak bir durum geçişi matrisi çıkarılmasına dayanır.

Önerilen markov tabanlı otomatik müzik besteleme yaklaşımında notalar ve ölçüler için iki ayrı markov zinciri oluşturulmuştur. Notalar için tanımlanan Markov zinciri basit olarak (1) denklemiyle ifade edilebilir.

$$
N_{\text {nota }}=\left(Q, \Sigma, \delta, q_{0}, \mathrm{~F}\right)
$$

Eşitlik (1)'de Q durumların kümesi olup (2) ifadesinde gösterilen notaları kapsamaktadır. $\Sigma$ notalar arası geçiş olasılıklarını, $\delta$ durum geçiş fonksiyonunu, $q_{0}$ başlangıç durumunu ve $\mathrm{F}$ son durumu göstermektedir. $q_{0}$ ve $\mathrm{F}$ herhangi iki nota olarak seçilebilir.

$$
Q=\{\text { Sus }, \ldots, C 3, C \# 3, D 3, D \# 3, E 3 \ldots\}
$$

Nota ölçüleri için oluşturulan markov zinciri ise Eşitlik (3) ile gösterilmiştir. Bu markov zincirinde R, Eşitlik (4) ile belirtilmiş nota ölçülerini kapsamaktadır. $\boldsymbol{r}_{0}$ başlangıç durumu ve G son durumu herhangi iki ölçü olarak seçilebilir.

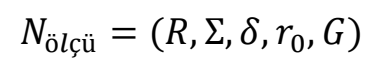




$$
R=\left\{\frac{1}{32}, \frac{1}{16}, \frac{1}{8}, \frac{1}{4}, \frac{1}{2}, 1\right\}
$$

Bir Markov zinciri, kendinden önceki $n$ adet durumu hatırlayabilir. $n$ adet durumu hatırlayabilen Markov zincirine $n$ 'inci mertebe Markov zinciri denir. İkinci mertebe Markov zincirleri, birinci mertebe Markov zincirlerine göre daha etkin sonuçlar vermektedir. Öte yandan, üçüncü mertebe Markov zincirlerinin hesaplama karmaşıklığının yükselmesi ve performans olarak ikinci mertebe Markov zincirleriyle aynı seviyede olması nedeniyle (Lo \& Lucas, 2006) bu çalışmada üçüncü mertebe Markov zincirleri değerlendirmeye alınmamıştır.

Önerilen sistemde uygulanacak Markov zinciri ikinci mertebeden olup, 127 nota ve bir sus notası arasındaki geçişleri modeller. Modellenen matris sus notası ve A'nın -2. oktavından başlayıp, G'nin 8. oktavına kadar uzanmaktadır.

Markov model ile çift enstrumanlı müzik besteleme sistemi, girdi olarak kullanılan eğitim müzik parçası ile markov model oluşturma ve oluşturulan markov model ile müzik besteleme olmak üzere iki ana aşamadan oluşmaktadır. Sistem adımları Şekil 2'de ayrıntılı olarak görülmektedir.

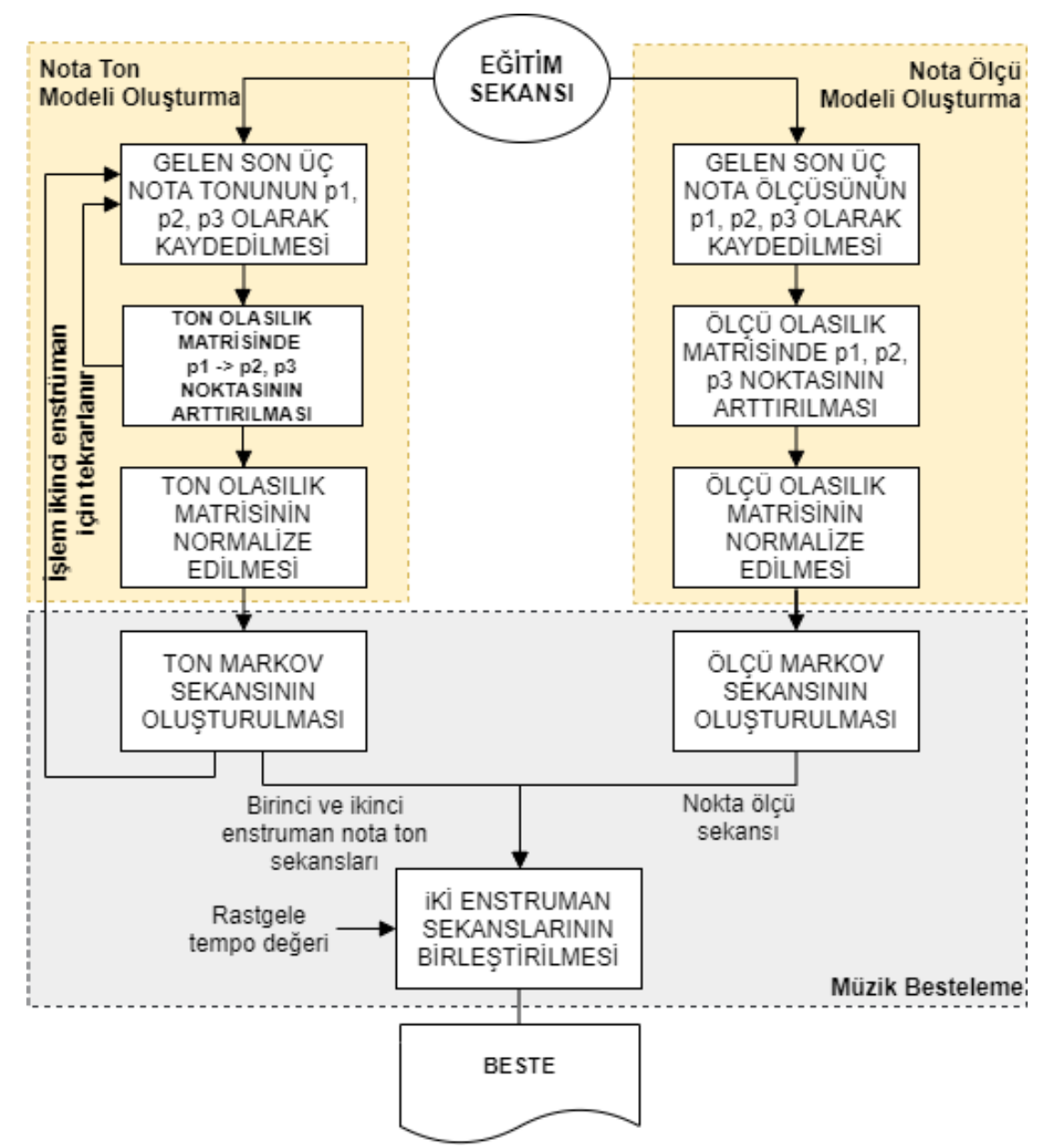

Şekil 2. Markov Modeli ile Çift Enstrumanlı Müzik Besteleme (Composition of Music with Dual Instruments by Using Markov Model)

Önerilen sistemde eğitim parçasının nota tonları ve ölçüleri kullanılarak nota ton ve ölçü modelleri oluşturulmaktadır. Her iki modelin oluşturulmasında da olasılık matrisi hesaplama ve normalizasyon adımları yer almaktadır. Model oluşturma adımının detayları Bölüm 3.1'de verilmiştir. Oluşturulan modeller kullanılarak Bölüm 3.2'de anlatılan müzik besteleme aşamasında önce birinci enstruman için sekans üretilir ardından bu sekansın modeli çıkartılarak ikinci enstrumana sekans üretmede kullanılır. İki sekansın ve rastgele belirlenen tempo değerlerinin birleştirilmesi ile çift enstrumanlı müzik besteleme işlemi tamamlanmış olur. 


\subsection{Markov Model Oluşturma (Markov Model Generation)}

Markov model oluşturma aşamasında notalar arası geçiş olasılıklarını ( $\boldsymbol{\Sigma}$ ) hesaplamak için, (5) ifadesinde verilen Markov geçiș matrisi üretilmektedir.

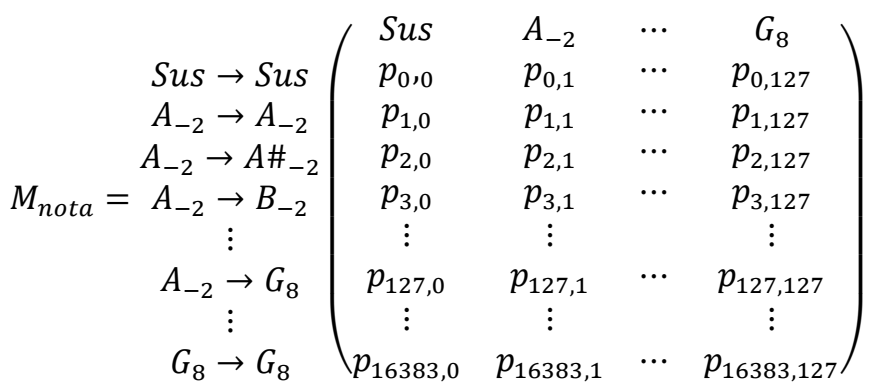

Eșitlik (5)'deki matriste her bir $p_{\mathrm{ij}}$, satırda belirtilen durumdan sütunda belirtilen duruma geçiș olasılığını göstermektedir. Birinci mertebeden bir Markov zinciri sadece son durumu kapsamaktadır. Bu çalıșmadaki Markov zinciri son iki durumu ele aldığından, matrisin boyutu (128x128)x128'dir.

Geçiş matrisi hücreleri başlangıçta 0 ile ilklendirilir. Girdi olarak kullanılan müzik parçasının notaları tek tek ele alınarak her iterasyonda şu anki duruma $\left(p_{n}\right)$, şu anki durumdan bir öncesine $\left(p_{n-1}\right)$ ve iki öncesine bakılır ( $\left.p_{n-2}\right)$ ve geçiş matrisinde $\left(\mathrm{p}_{\mathrm{n}-2}->\mathrm{p}_{\mathrm{n}-1}, \mathrm{p}\right)$ hücresi 1 arttırılır.

Önerilen modelde nota ölçüleri için ikinci bir ikinci dereceden Markov zinciri uygulanmaktadır. Modellenen matris altı farklı nota ölçüsüne bölünmüștür: Otuzikilik ölçü, onaltılık ölçü, sekizlik ölçü, dörtlük ölçü, yarım ölçü ve tam ölçü. Girdi müzik parçasının nota ölçüleri için oluşturulan Markov geçiş matrisi Eşitlik (6)'da gösterilmiştir. Bu matris de nota ton geçişleri için oluşturulan matris ile aynı yöntemle, ancak bu kez eğitim için kullanılan müzik parçasının nota ölçüleri taranarak oluşturulur.

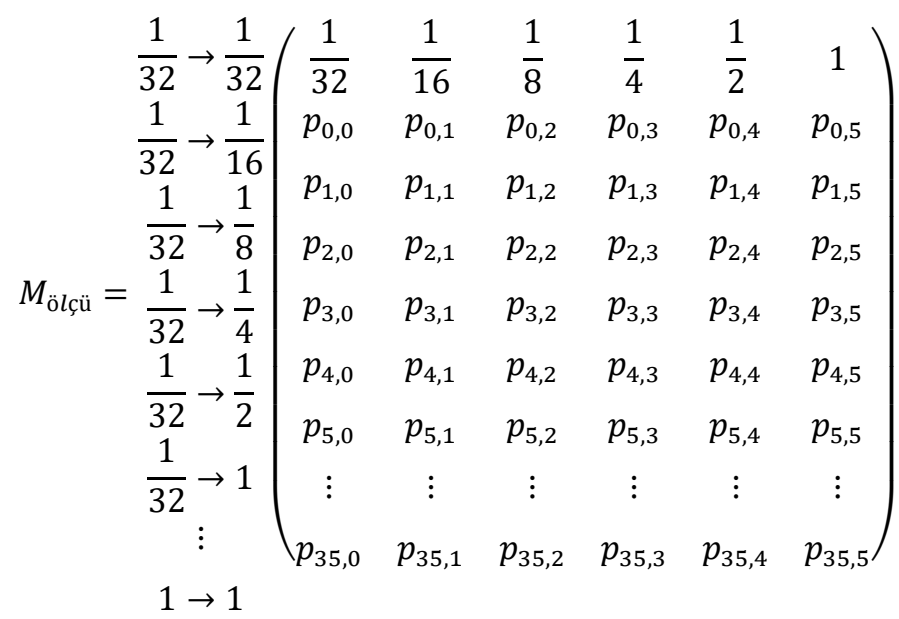

Eğitim aşamasının son adımında, oluşturulan nota ve nota ölçü geçiş matrisleri (7) bağıntısı ile normalize edilmektedir. Normalizasyon, matrisin her satırındaki bütün olasılık durumlarının toplanması ve sonra her satır için olasılıkların bu toplama bölünmesi ile yapılmaktadır.

$$
p_{i j_{\text {normalize }}}=\frac{p_{i j}}{\sum_{j} p_{i j}}
$$

\section{2 Çift Enstrumanlı Müzik Besteleme (Composition of Music with Dual Instruments)}

Nota ve ölçüleri için normalize edilmiş geçiş matrisleri hesaplandıktan sonra bu modeller kullanılarak müzik besteleme aşamasına geçilmektedir.

$\mathrm{Bu}$ aşamada tonlar ve ölçüler için Markov zincirinin geçiş fonksiyonu $\boldsymbol{\delta}$ kullanılarak ayrı birer sekans oluşturulmaktadır. Bunun için aralarındaki geçiş olasılığı yüzde sıfır olmamak şartıyla ilk iki nota rastgele olarak seçilir. Geçiş fonksiyonu, sıradaki her nota için $\boldsymbol{M}_{\text {nota }}$ matrisinde $(n-2 \rightarrow n-1, n)$ 'e denk gelen olasılıklardan en 
yükseğini veren notayı seçerek yeni bir sekans üretir. Sekans, 60 adet ile 120 adet arasında durum geçişi ürettikten sonra durdurulur.

Bu durum geçiși aralığının kullanılmasının sebebi, üretilmiș bir bestenin uzunluğunun ortalama 15-30 saniye arasında olmasının sağlanmasıdır. Genelde 15-30 saniyelik melodiler kişilerde akılda kalıcılığı arttırmaktadır, çünkü tonaliteyi sağlamak uzun melodilerde daha güçtür (Long, 1977).

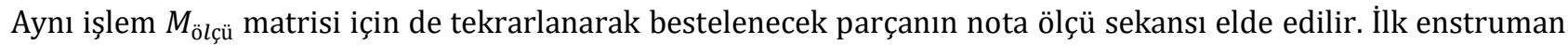
için bestelenen müzik parçası, üretilen nota ve nota ölçü sekanslarının birleştirilmesi ile oluşmaktadır.

Sonraki adımda ikinci enstruman için yeni bir model oluşturmak ve bu yeni modelden ilk enstruman ile uyumlu bir ikinci enstruman sekansı üretmek amacıyla, birinci enstruman için üretilen nota sekansı tekrar Markov model oluşturma sürecine girdi olarak verilir.

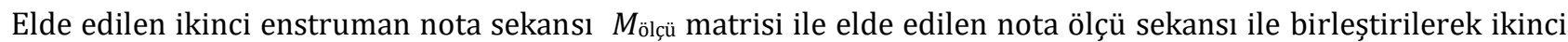
enstrüman müzik çıktısı oluşturulur. Bu şekilde ikinci enstrümanın, birinci enstrümana bağlı bir nota dizilimi üretmesi sağlanır. İkinci enstrümanın, birinci enstrümanın Markov modeli üzerinden yeniden eğitilerek kullanılmasındaki amaç, müzikal armoninin arttırılmasıdır.

En son aşamada rastgele seçilen bir tempo değeri ve iki enstrüman için rastgele iki sanal enstrüman belirlenerek, oluşturulan nota ton ve ölçü sekansları birleştirilerek çift enstrumanlı beste oluşturulur.

\section{Deneysel Sonuçlar (Experimental Results)}

Markov modeline girdi olarak verilen ve bestelenen müzik parçalarının nota sekansları MIDI (Musical Instrument Digital Interface) formatında tutulmaktadır. MIDI, elektronik ortamda müzik bilgisinin metinsel olarak kodlanmasında kullanılan bir iletişim protokolüdür. MIDI dosyaları ses sinyali içermemektedir, ses sinyalleri yerine notalarla ilgili mesajlar içermektedir. Bir sanal çıkış cihazı, MIDI sekanslarını okuyarak anlık olarak ses dosyaları üretebilmektedir. Birinci ve ikinci enstruman için Markov model ile oluşturulan sekanslar MIDI sanal çıkıș cihazına gönderilir. MIDI çıkıș cihazına gönderilen değerler aynı $n$. nota için iki farklı enstrümanda aynı ölçüde çalınır.

Markov süreciyle müzik üretimi için kodlama C\# ile gerçekleştirilmiş olup Leslie Sanford'a ait C\# MIDI Toolkit kütüphanesinden yararlanılmıştır (Sanford, 2007). Besteleme süreci ile oluşturulan MIDI dosyaları Microsoft GS Wavetable Synth sanal çıkış cihazı ile çalınmaktadır.

Önerilen sistemin performanısını değerlendirmek amacı ile Markov zincirlerinin çeşitli uygulamaları anketlerle test edilmiş, bir adet somut örnekle desteklenmiştir. Sistem performansı öznel niteliklerinden dolayı otomatik olarak ölçülemeyeceğinden, Turing testi ve iki farklı beğeni testi olmak üzere, üç farklı anket uygulanmıştır.

Testlerden ilki Turing testidir. Turing testinde amaç, bir insanın, makine tarafından üretilen çıktının bir insan besteciye mi, yoksa makineye mi ait olduğunun ayrımını yapıp yapamadığını ölçmektir. Turing testi için farklı yaş gruplarından 51 dinleyiciye 9'u Markov süreciyle, 4'ü insan eliyle üretilmiş 13 farklı parça dinletilmiştir. Daha sonra dinleyicilere bu parçaların insan yapımı olup olmadığı sorulmuştur. 9 parça içinde yanlış sınıflandıranlar ya da kararsız kalanların oyları performans analizinde başarılı olarak sayılmıştır.Tablo 1'de Turing testinin sonuçları yer almaktadır. Turing testinde ortalama \%43'lük bir başarı elde edilmiştir.

Tablo 1. Turing Testinin Sonuçları (Results of Turing Test)

\begin{tabular}{|c|c|}
\hline Parça & Yanlış/Kararsız Sınıflandırma Oranı \\
\hline 1 & $\% 35.294$ \\
2 & $\% 41.176$ \\
3 & $\% 23.529$ \\
4 & $\% 56.863$ \\
5 & $\% 80.392$ \\
6 & $\% 21.569$ \\
7 & $\% 35.294$ \\
8 & $\% 72.549$ \\
9 & $\% 21.569$ \\
\hline Ortalama & $\% 43.137$ \\
\hline
\end{tabular}

Testlerden ikincisi beğeni testi olup, aynı 51 dinleyiciye Markov süreciyle üretilmiş 20 parça dinletilmiştir. Dinleyicilerden en kötü 1, en iyi 10 olmak üzere Rock, Blues, Klasik ve Pop olmak üzere dört farklı müzik türünden eğitim parçaları kullanılarak otomatik olarak bestelenen parçaları puanlandırmaları istenmiştir. Tablo 2 'de beğeni 
testinin sonuçları, varyansları ve elde edilen müziğin eğitim verisinin uzunluğu yer almaktadır.

Tablo 2. Dört Farklı Müzik Türü İçin Yapılmış Beğeni Testinin Sonuçları (The Results of the Liking Test for Four Different

\begin{tabular}{|c|c|c|c|c|}
\hline Parça & Tür & Beğeni & Varyans(б) & Orijinal Müzik Uzunluğu \\
\hline 1 & Rock & 6.51 & 3.94 & $3: 52$ \\
2 & Rock & 4.64 & 4.55 & $2: 43$ \\
3 & Rock & 2.77 & 3.45 & $5: 12$ \\
4 & Rock & 3.84 & 3.72 & $6: 36$ \\
5 & Rock & 3.55 & 2.57 & $4: 25$ \\
6 & Blues & 4.27 & 3.26 & $3: 00$ \\
7 & Blues & 6.68 & 4.49 & $3: 48$ \\
8 & Blues & 3.84 & 4.13 & $4: 50$ \\
9 & Blues & 5.39 & 4.74 & $7: 42$ \\
10 & Blues & 3.66 & 3.72 & $5: 34$ \\
11 & Klasik & 3.78 & 2.68 & $0: 55$ \\
12 & Klasik & 4.05 & 4.59 & $1: 29$ \\
13 & Klasik & 6.14 & 5.39 & $7: 14$ \\
14 & Klasik & 4.89 & 4.96 & $3: 36$ \\
15 & Klasik & 7.77 & 4.08 & $0: 35$ \\
16 & Pop & 5.08 & 4.19 & $0: 38$ \\
17 & Pop & 5.48 & 4.93 & $3: 07$ \\
18 & Pop & 5.45 & 2.84 & $4: 50$ \\
19 & Pop & 5.43 & 4.43 & $4: 13$ \\
20 & Pop & 3.68 & 6.26 & $5: 17$ \\
\hline \multicolumn{2}{|c|}{ Ortalama } & 4.84 & 4.15 & \\
\hline
\end{tabular}

Beğeni testi 10 üzerinden 4.84 ortalamaya sahiptir. Orijinal müzik uzunluğu ile beğeni miktarı ve varyansı arasındaki korelasyonu araştırmak amacı ile beğeni testi için üretilen 20 parça'nın eğitim parçaları araştırılmıştır. İlgili verilerin grafiği Şekil 3'te verilmiştir. Dikey eksen üretilen müziğin eğitim parçasının uzunluğunu belirtmektedir. Grafikten çok uzun süreli eğitim verilerinin beğeniyi düşürdüğü çıkarımı yapılabilir. Özellikle beş dakikadan uzun eğitim verilerinde beğeni ortalamasının 5'in altına düştüğü görülmektedir.

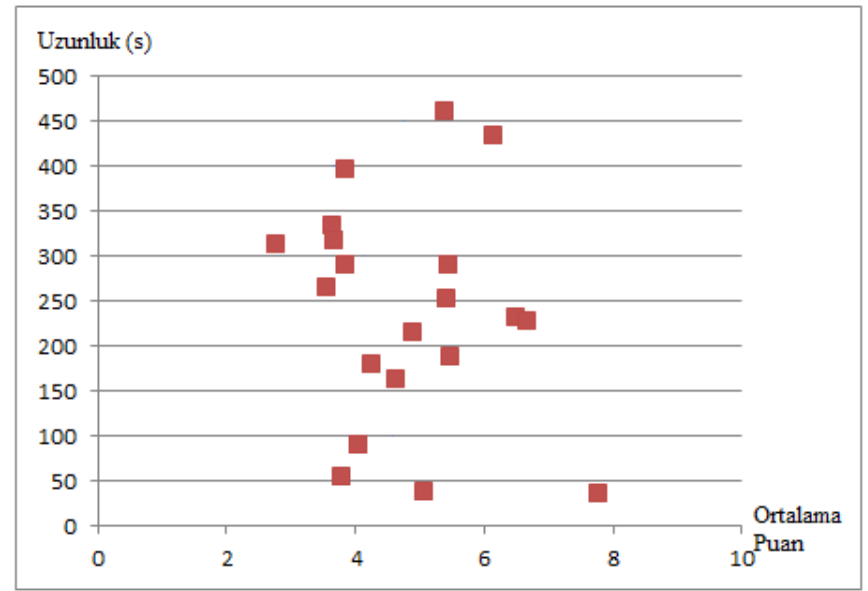

Şekil 3. Orijinal Müzik Uzunluğu İle Beğeni Puanı Arasındaki Korelasyon (Correlation Between Original Music Length and Liking Score)

Üçüncü test, eğitim için kullanılacak müzik kesitinin uzunluğunun üretilen müzik sekansına etkisini incelemek için yapılmıştır. Bu amaçla dört farklı müzikten dokuzar beste üretilmiştir. Bu bestelerin eğitim süreleri sırasıyla 10, $20,40,60,90,120,180,240$ ve 300 saniyedir. Bu besteler 10 farklı kişiye dinletilerek 1 ile 10 arasında puanlandırılması sağlanmıștır. Sonuç grafiği Şekil 4 'te verilmiștir.

En çok beğenilen Rock müzik çıktısı 120 saniyelik eğitim verisinin çıktısıdır. En çok beğenilen klasik müzik çıktısı 240 saniyelik eğitim verisinin çıktısıdır. Blues için en çok beğenilen çıktı 40 saniye için olmuştur. Son olarak, Pop müzik için en çok beğenilen çıktı 240 saniyelik eğitim verisinin çıktısıdır. Bu grafikten yola çıkılarak, beş dakikalık müziklerin beğeniyi düşürdüğü söylenebilir. Aynı zamanda, çok kısa eğitim sürelerinde beğeni oranının düşük olduğu gözlemlenebilmektedir. Şekil 4'te görüldüğü gibi ortalama beğeni eğrisi bir noktaya kadar artış 
gösterirken, 120. saniyeden sonra alternatif bir şekilde düşüp yükselmektedir. İkinci beğeni testinde 120 saniyelik müzik parçalarından üretilen sekansların beğeni ortalaması 6.2 iken genel ortalama 5.62'dir.

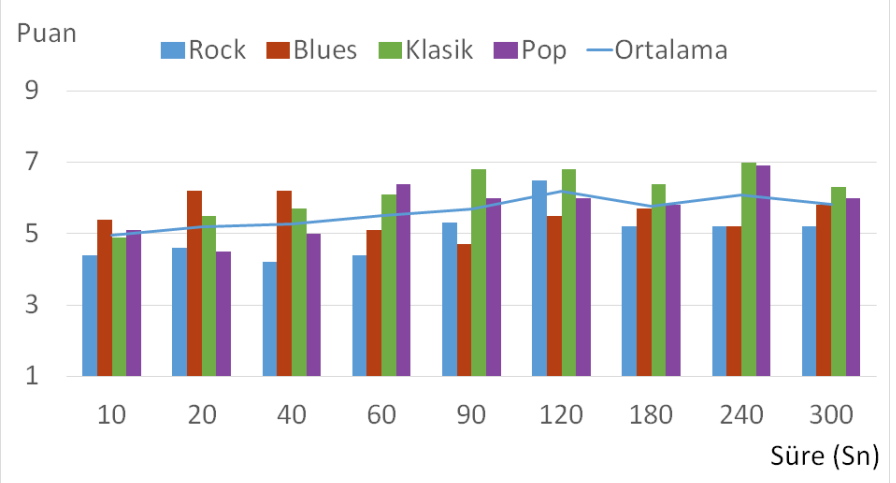

Şekil 4. Eğitimde Kullanılan Müzik Kesiti Uzunluğuna Bağlı Beğeni Skorları (Liking Scores Based on the Length of the Music Section Used in Training)

Elde edilen 6.2'lik beğeni puan, ilk beğeni testi ortalaması olan 4.84'ten daha iyi bir başarıdır. Eğitim için kullanılacak müzik parçası kesitlerinin uzunluklarının 120 sn olarak belirlenmesi, detayları Tablo 2'de verilmiş beğeni testi ortalama puanının da artmasını sağlayacaktır.

Ne yazık ki geliştirilen sistemin başarısının literatürdeki diğer çalışmaların başarıları ile adil olarak karşılaştırılması, eğitim için kullanılan müzik parçalarının ve ankete katılan kişilerin farklılıkları sebebi ile mümkün olamamıştır. Elde edilen beğeni ve Turing testi sonuçlarına baktığımızda, önerilen Markov model ile çift enstrumanlı müzik besteleme sisteminin yine Markov zinciri kullanan Van der Merwe'nin yüzde 38 başarısına göre (Van der Merwe, 2011) daha yüksek başarı elde ettiği gözlenmiştir. Bu gözlem bizi çift enstruman kullanmanın sadece Markov tabanlı sistemlerin değil farklı metodolojiler izleyen sistemlerin de başarısını arttırabileceği sonucuna götürmektedir. Öte yandan, elde edilen başarı oranları daha yüksek karmaşıklığa sahip ve tek enstrüman kullanan Roig'in çalışmasındaki \%64 başarıyla kıyaslanabilir düzeydedir (Roig, 2018).

Eğitim için kullanılan parçalar ile önerilen sistemin otomatik olarak ürettiği parçaların birbirlerine ne derecede benzediğini görsel olarak ortaya koyabilmek için Şekil 5'de Mozart'ın Marcia Alla Turca parçası ve bu parçadan üretilmiş müzik parçasınn kesitleri verilmiştir. Şekil 5(a)'da Marcia Alla Turca parçasının bir kesiti yer almaktadır. Parçada gözlemlenen nota ton örüntüleri incelendiğinde notalarda kullanılan ölçülerin çeyrek, sekizlik ve on altılık olduğu, sus notalarının ise on altılık ve çeyrek ölçüde olduğu görülebilir. Şekil 5(b)'de ise Markov süreciyle bestelenen parçanın bir kesiti yer almaktadır. Üretilen parça incelendiğinde yine notalarda kullanılan ölçülerin çeyrek, sekizlik ve on altılık olduğu gözlemlenebilir. Üretilen parça ve Marcia Alla Turca'nın notalarının kullanım sayıları Tablo 3 'te belirtilmiştir.

Tablo 3. Marcia Alla Turca'da ve Markov Süreci ile Üretilen Müzikte Notaların Görülme Sıklıkları (Frequency of Notes in Marcia Alla Turca and Music Produced by Markov Process)

\begin{tabular}{|c|c|c|}
\hline Nota & Marcia Alla Turca'da notalarn görülme sıklığı & Markov süreci ile üretilen müzikte notaların görülme sıklığı \\
\hline C & 23 & 21 \\
D & 2 & 2 \\
D\# & 1 & 0 \\
E & 12 & 12 \\
F & 6 & 1 \\
F\# & 1 & 0 \\
G & 7 & 4 \\
G\# & 3 & 7 \\
A & 21 & 25 \\
B & 9 & 10 \\
\hline
\end{tabular}

Orijinal müzik ve bu müzikten çıkarılan model ile bestelenen parçada notaların görülme sıklıkları karşılaştırıldığında, üretilen parçada orijinal parçada görülen D\# ve F\# notalarının artık yer almadığı görülebilir. Aynı zamanda notaların kullanım sıklıklarının benzer sayılarda olduğu, A ve C notalarının orijinal parçadaki gibi en çok kullanılan notalar olduğu gözlemlenebilir.

Eğitim parçası ve üretilen parçanın notalarında benzer örüntülere rastlamak mümkündür. Şekil 5 'te $M a r c i a ~ A l l a$ Turca ile sistem tarafından üretilen parça arasında eşleşen örüntüler, her iki parçada aynı renkli kutularla gösterilmiştir. Sonuç olarak, Markov süreci ile elde edilen bestelerde nota örüntülerinde ve nota tonlarında 
benzerlik görülmesine karşın, nota ölçülerinin değişim göstermesi ve orijinal parçada görülen nota örüntülerinin kendi içinde yer değiştirmeleri sayesinde, orijinal parçadan farklı bir sekans ortaya çıkması sağlanmaktadır.

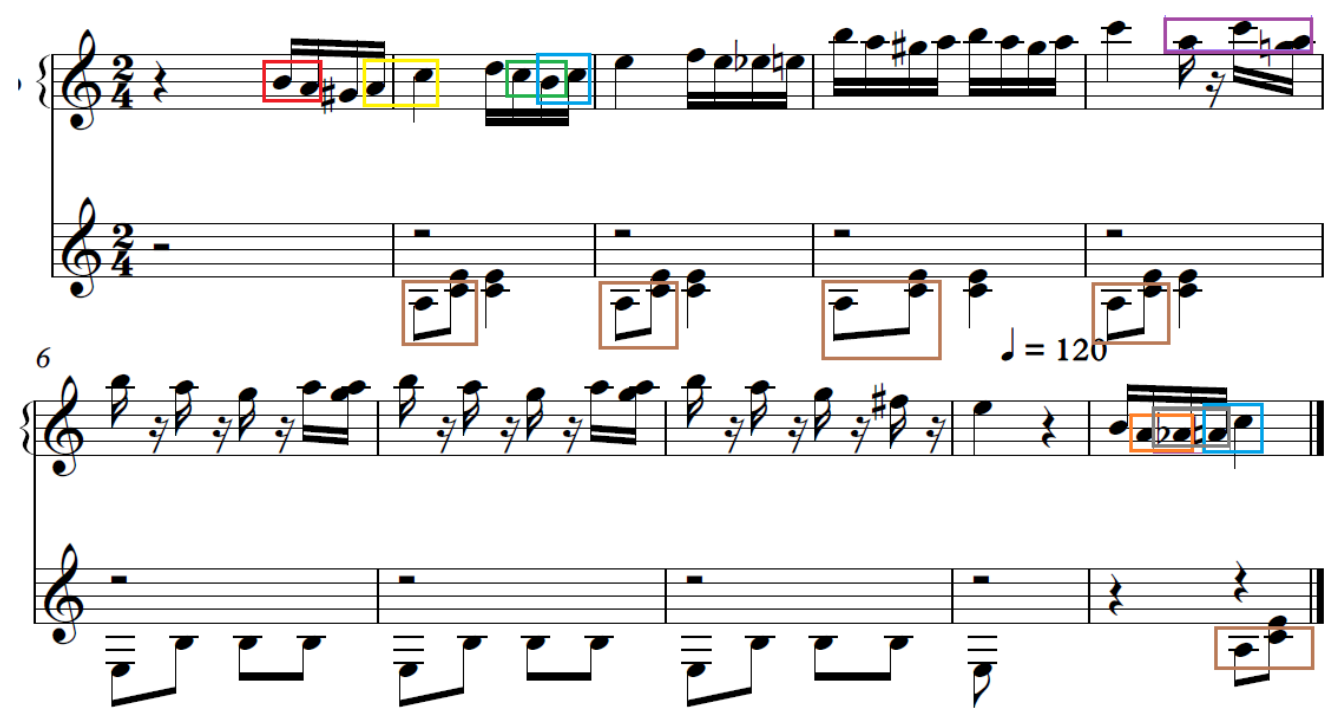

(a)

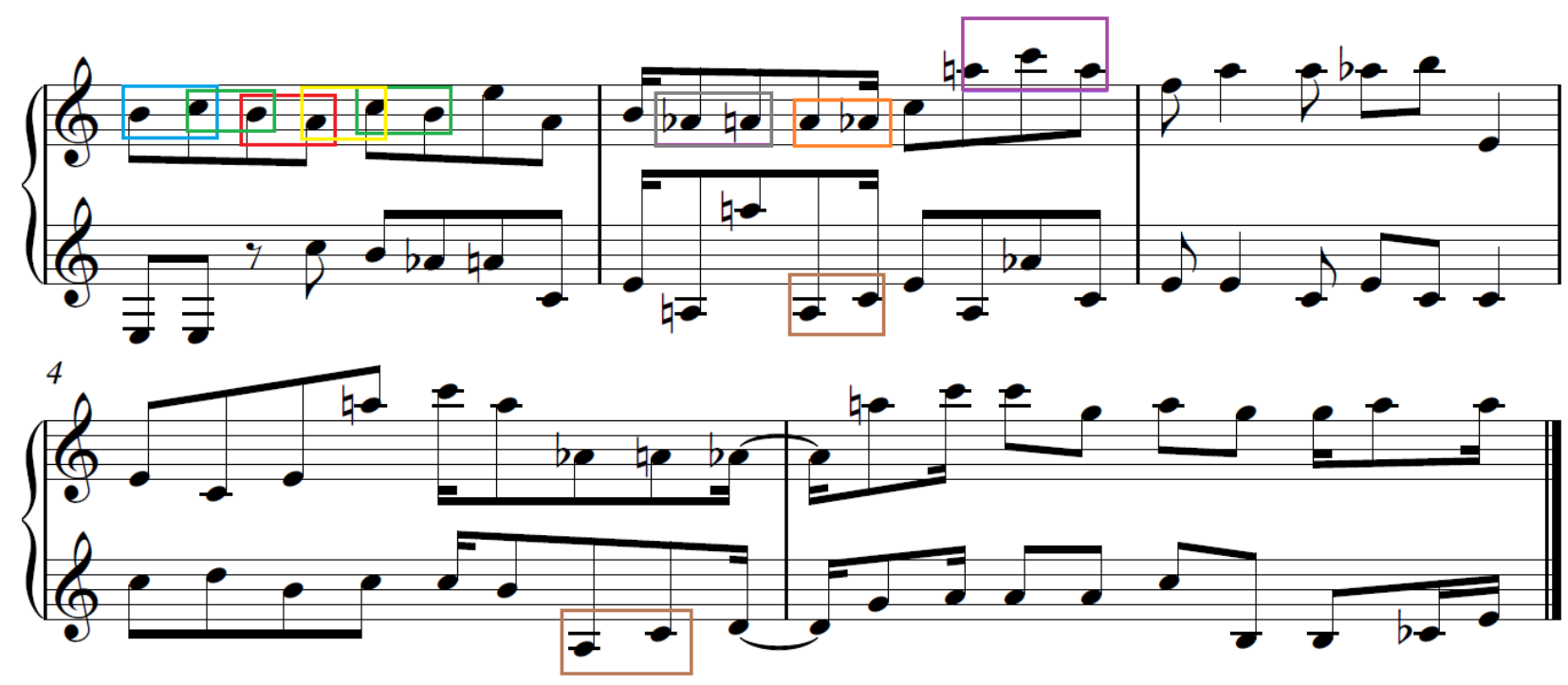

(b)

Şekil 5. Nota Örüntüsünde Eşleşmeler. (a) Marcia Alla Turca (b) Markov Süreci ile Üretilen Müzik Parçası (Matches in the Note Pattern (a) Marcia Alla Turca (b) Music Piece Composed by Markov Process )

\section{Sonuç ve Tartışma (Result and Discussion)}

Bu çalışmada, Markov zincirlerinin kullanımı ile çeşitli besteler elde edilmiştir. Markov zincirlerinin elde edilmesinde iki farklı ana parametre kullanılmıştır: Nota ölçüleri ve nota tonları. Elde edilen bütün besteler, aynı anda iki enstrüman kullanmaktadır ve bestelerde iki enstrümanın nota ölçüleri aynı zaman içinde eşittir. Üretilen parçalarda bir enstrüman aynı anda bir nota sesi çıkartabilmektedir. Önerilen modelin düşük hesaplama karmaş̧ıklığına sahip olması, sistemin son yıllarda populerliği oldukça artan mobil cihazlara uygulanabilirliğini kolaylaştırmaktadır.

Anketin sonuçlarından yola çıkılarak insan yapımı müziklerin, bilgisayar yapımı müziklere tercih edildiği gözlenmekle birlikte Turing testinden elde edilen sonuçlar oldukça umut vericidir. Projede yeni üretilen müzikler, kendilerine ait insan yapımı girdilerle notaların örüntüleri ve kullanım sayıları açısından benzerlik göstermektedir, yine de bilgisayarla üretilmiş beste kendi içinde bir özgünlük sağlamaktadır.

Farklı enstrümanların birbirine bağlı olarak eğitilerek kullanılıyor oluşunun tek enstrüman veya birbirinden bağımsız enstrümanlara göre daha iyi sonuç verdiği gözlemlenmiştir. Birbirinden etkilenen iki enstrüman için sekans üretilmesi optimizasyona dayalı müzik besteleme sistemlerinin de başarısını arttıracaktır. Eğitim parçasının orijinal uzunluğunun ve eğitim için kullanılacak kesitinin süresinin, üretilen müziğin performansına 
etkisi ortaya konmuştur. Elde edilen analiz sonuçları literatürdeki diğer otomatik müzik besteleme yöntemlerinin iyileştirilmesine katkı sağlayabilir. Ayrıca çalışmamız, insan makine etkileşimini daha efektif hale getirmektedir.

İleride bu çalıșmaya ek olarak bestelerin üretiminde zaman ișaretleri dahil edilebilir ve üretilen iki enstrümanın aynı zamanda farklı nota ölçüleri basması sağlanabilir. Notaların geçişleri arasındaki örüntüler üstünde kuraltabanlı sistemler ve optimizasyon yöntemleri uygulanabilir. Otomatik müzik bestelemenin geleceğinin açık olmasıyla birlikte, daha farklı yöntemlerin keşfedilmesiyle daha başarılı sonuçlar elde edilmesi beklenmektedir.

\section{Çıkar Çatışması (Conflict of Interest)}

Yazarlar tarafından herhangi bir çlkar çatışması beyan edilmemiştir. No conflict of interest was declared by the authors.

\section{Kaynaklar (References)}

Ames, C. (1987). Automated composition in retrospect: 1956-1986. Leonardo, 20 (2), 169-185.

Ariza, C. (2011). Two pioneering projects from the early history of computer-aided algorithmic composition. Computer Music Journal, 35 (3), 40-56.

Boenn, G., Brain, M., De Vos, M., \& Ffitch, J. (2011). Automatic music composition using answer set programming. Theory and practice of logic programming, 11 (2-3), 397-427.

Burton, A. R., \& Vladimirova, T. (1999). Generation of musical sequences with genetic techniques. Computer Music Journal, 23 $(4), 59-73$

Chen, C.-C., \& Miikkulainen, R. (2001). Creating me-lodies with evolving recurrent neural networks. In Neural networks, 2001. proceedings. ijcnn'01. international joint conference on (Vol. 3, pp. 2241-2246)

Colombo, F., Muscinelli, S. P., Seeholzer, A., Brea, J.,\& Gerstner, W. (2016, June). Algorithmic Composition of Melodies with Deep Recurrent Neural Networks. ArXiv e-prints.

de la Puente, A. O., Alfonso, R. S., \& Moreno, M. A. (2002). Automatic composition of music by means of grammatical evolution. In Acm sigapl apl quote quad (Vol. 32, pp. 148-155).

Frequencies of musical notes, a $4=440$ hz.(n.d.). Retrieved from https://pages.mtu.edu/ suits/notefreqs.html

Garcia Salas, H. A., Gelbukh, A., Calvo, H., \& Galindo Soria, F. $(2011,12)$. Automatic Music Composition with Simple Probabilistic Generative Grammars. Polibits, 59 - 65.

HEDGES, S. A. (1978). Dice music in the eighteenth century. Music and Letters, 59 (2), 180-187. doi: 10.1093/ml/59.2.180

Herremans, D., Weisser, S., Sörensen, K., \& Conklin,D. (2015). Generating structured music for bagana using quality metrics based on markov models. Expert Systems with Applications, 42 (21), $7424 \quad-\quad 7435$. doi: https://doi.org/10.1016/j.eswa.2015.05.043

Hiller, L. A., \& Baker, R. A. (1964). Computer cantata: A study in compositional method. Perspectives of New Music, 3 (1), $62-$ 90.

Holtzman, S. R. (1981). Using generative grammars for music composition. Computer Music Journal, 5 (1), 51-64

Hornel, D., \& Menzel, W. (1998). Learning musical structure and style with neural networks. Computer Music Journal, 22 (4), 44-62.

Lo, M., \& Lucas, S. M.(2006). Evolving musical sequences with n-gram based trainable fitness functions. In 2006 ieee international conference on evolutionary computation (p. 601-608). doi: 10.1109/CEC.2006.1688365

Long, P. (1977). Relationships between Pitch Memory in Short Melodies and Selected Factors. Journal of Research in Music Education, 25(4), 272-282. Retrieved from http://www.jstor.org/stable/3345268

Mazurowski, L. (2012, Sept). Computer models for algorithmic music composition. In 2012 federated conference on computer science and information systems (fedcsis) (p. 733-737).

Merwe, A. V. D., \& Schulze, W. (2011, March). Music generation with markov models. IEEE MultiMedia, 18 (3), 78-85. doi: 10.1109/MMUL.2010.44

Muñoz, E., Cadenas, J. M., Ong, Y. S., \& Acampora, G. (2016, Feb). Memetic music composition. IEEE Transactions on Evolutionary Computation, 20 (1), 1-15. doi: 10.1109/TEVC.2014.2366871

Papadopoulos, A., Roy, P., \& Pachet, F. (2014). Avoiding plagiarism in markov sequence generation. In Proceedings of the twenty-eighth aaai conference on artificial intelligence (pp. 2731-2737). AAAI Press.

Roig, C., Tardón, L. J., Barbancho, I., \& Barbancho, A. M. (2014). Automatic melody composition based on a probabilistic model of music style and harmonic rules. Knowledge-Based Systems, 71, $419-434$

Roig, C., Tardón, L. J., Barbancho, I., \& Barbancho, A. M. (2018). A non-homogeneous beat-based harmony markov model. Knowledge-Based Systems, 142, 85 - 94. doi: https://doi.org/10.1016/j.knosys.2017.11.027

Sanford, L., (2007). C\# MIDI Toolkit https://www.codeproject.com/Articles/6228/C-MIDI-Toolkit

Tanaka, T., Nishimoto, T., Ono, N., \& Sagayama, S. (2010). Automatic music composition based on counterpoint and imitation using stochastic models.

Toivanen, J. M., Toivonen, H., \& Valitutti, R. (n.d.). Automatical composition of lyrical songs.

Westergaard, P., \& Hiller, L. A. (1959). Journal of Music Theory, 3 (2), 302-306.

Zhao, Y., Liu, L., Huang, Y., \& Fang, N. (2019). Automatic Composition of Music by LSTM. In 2018 International Workshop on Education Reform and Social Sciences. Atlantis Press. 
Ek:

\section{Temel Müzik Teorisi (Supplementary Material: Basic Music Theory)}

Nota, belli bir zaman uzunluğuna ve belli bir frekansa sahip bir ses parçasıdır. Müzik, basitçe notaların yan yana getirilmelerinden meydana gelir. Bu notalar arasında belli boşluklar bulunabilir. Bu boşluklara sus adı verilir.

Batı müziğindeki notalar, oktav denen gruplar içinde toplanmıştır. Her oktavın içinde ise temelde 7 ana, 5 ara olmak üzere toplam 12 nota bulunmaktadır. Tablo 4'te notalar ve dördüncü oktavdaki frekans karşılıkları verilmiştir(Frequencies of Musical Notes, $A 4=440 \mathrm{~Hz}, n$. d.).

Tablo 4. Notalar ve Frekans Karșılıkları (Notes and Corresponding Frequencies)

\begin{tabular}{|c|c|c|}
\hline Nota & Okunuş & Frekans (Hz) \\
\hline C & Do & 262 \\
\hline C\# & Do Diyez & 277 \\
\hline D & Re & 294 \\
\hline D\# & Re Diyez & 311 \\
\hline E & Mi & 330 \\
\hline F & Fa & 349 \\
\hline F\# & Fa Diyez & 370 \\
\hline G & Sol & 392 \\
\hline G\# & Sol Diyez & 415 \\
\hline A & La & 440 \\
\hline A\# & La Diyez & 466 \\
\hline B & Si & 494 \\
\hline
\end{tabular}

"\#" işareti, diyez diye okunur ve belirtilen nota ile kendinden sonraki notanın arasında bulunduğunu ifade eder. E ve B notalarının diyez işareti yoktur. Aynı zamanda "b" işareti de bulunur, bemol diye okunur ve belirtilen nota ile kendinden önceki notanın arasında bulunduğunu ifade eder. F ile C notalarının bemol işareti yoktur. Her oktavın notaları, kendinden önceki oktavın iki katı, kendinden sonraki oktavın yarısı frekansa sahiptir.

Tek bir parçada 12 nota aynı anda bulunamayabilir. Bazı notalar birbirleri arasında uyum içindedir. Bu uyumlu notaların toplandığı gruplara gam denir. Her gam kendine bir notayı anahtar adı verilen ana ton olarak seçer ve diğer notalar ile olan göreceli ilişkisine göre gruplanır. Örneğin, C Majör gamı her oktavdaki C, D, E, F, G, A, B notalarını kapsarken; D Majör gamı her oktavdaki D, E, F\#, G, A, B, C\# notalarını kapsar.

Notaların uzunlukları birbirlerinin katı şeklindedir. Bu uzunluklar tempo ile ilișkilidir ve tempo BPM (beats per minute) birimiyle ölçülür. Bu ölçüte göre 1 BPM'de tam bir nota ölçüsü bir dakika, 2 BPM'de tam bir nota ölçüsü otuz saniye, 60 BPM'de tam bir nota ölçüsü bir saniye sürmektedir. Standart bir şarkı temposu 120 BPM'dir. Notalarda ölçüler; tam, yarım, dörtlük, sekizlik, on altılık, otuz ikilik şeklinde 2'nin negatif kuvvetlerine orantılı olarak azalmaktadır. Örneğin, 120 BPM'de tam ölçü 500 milisaniye, yarım ölçü 250 milisaniye, dörtlük ölçü 125 milisaniyedir.

Notalar bir şarkı içinde ölçü çizgileri içinde gruplandırılır. Ölçü çizgileri içindeki nota uzunlukları tamamen sabittir ve bu ölçü çizgilerindeki zaman uzunlukları zaman işaretiyle belirlenir. Zaman işareti kesirli bir oran şeklinde belirtilir. Payda, notanın ölçüsünü belirler. Pay, paydadaki ölçüdeki notalardan kaç tane bulunduğunu belirler. Örneğin ${ }_{4}^{4}$ dendiğinde 4 adet dörtlük ölçüde nota bulunduğu, ${ }_{8}^{3}$ dendiğinde 3 adet sekizlik ölçüde nota bulunduğu anlaşılır. Ölçü çizgisinin içinde 4 adet dörtlük nota bulunmak zorunda değildir. Zaman işareti, bulunan notaların toplamda bu zaman uzunluğunda olması gerektiğini belirtir.

Notaların basılması sonucu verdiği düz sese vuruş adı verilir. Eğer nota basıldıktan sonra yukarıya doğru bir tonda gidiyorsa yukarı vuruş, eğer nota basıldıktan sonra aşağıya doğru bir tonda gidiyorsa aşağı vuruş ismini alır.

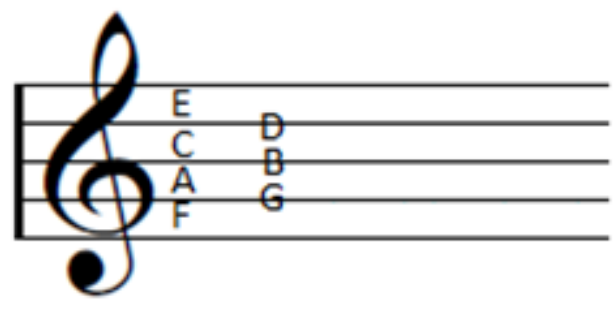

Şekil 6. Notaların yerleri (Location of Notes) 
Aynı anda ve aynı uzunlukta basılan, aynı enstrümandaki en az iki noktaya akor adı verilir. Akorlar, tuşlu enstrümanlara göre en soldaki notayı referans alan isimlere sahiptir. Örneğin C akoru, C, E ve G notalarının aynı anda basıldığını ifade eder.
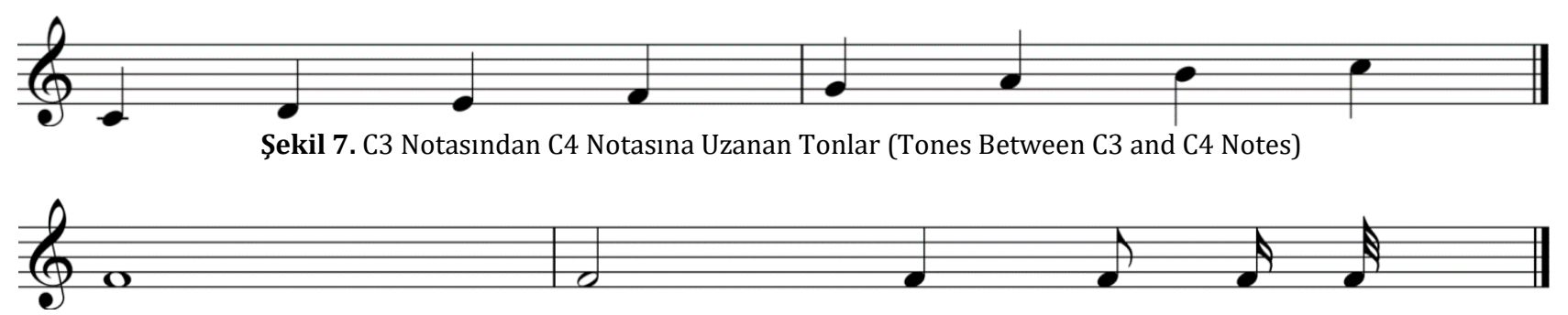

Şekil 8. Notaların Uzunlukları (Note Lengths)

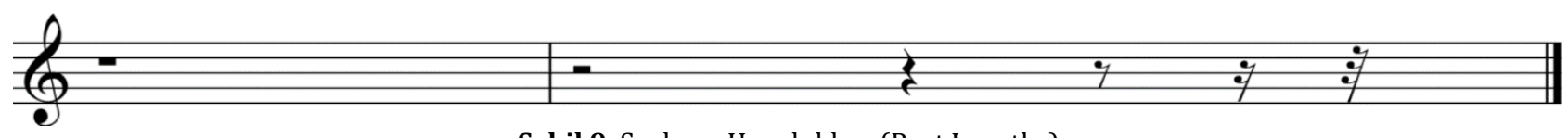

Şekil 9. Susların Uzunlukları (Rest Lengths)

Nota kâğıtları okunurken dikkat edilmesi gereken üç kavram vardır: Nota anahtarı, nota tonu ve nota ölçüsü. Nota anahtarının şekli, notaların nasıl sıralanması gerektiğini göstermektedir. Şekil 6'da G (sol) anahtarı için her tonun bulunması gereken yer belirtilmiştir. Şekil 7'da örnek olarak G anahtarına göre C3 notasından itibaren C4 notasına kadar ara tonlar haricindeki tonlar verilmiştir. Bir ara ton belirtilmesi gerekiyorsa, ara ton bemol için "b", diyez için "\#", sonraki notanın diyez ya da bemol olmadığını belirtmek için " " kullanılır. Buna natürel nota da denir.

Notaların ölçülerini belirten notasyonlar Şekil 8'de verilmiştir. Şekil 9'de ise sus notaları için gerekli notasyonlar belirtilmiştir. Bu notasyonlar sırasıyla tam, yarım, çeyrek, sekizlik, on altılık ve otuz ikilik ölçüleri göstermektedir.

Önerilen sistem tarafından bestelenmiş müzik parçalarından örneklere ve bu parçaların üretilmesi için kullanılan eğitim sekanslarına https://github.com/hiremt/COMPOSITION-OF-MUSIC-WITH-DUAL-INSTRUMENTS-BASEDON-MARKOV-MODEL adresinden erişilebilir. 